\title{
Trend Analysis of Water Pollutant at Summer Rainfall Season
}

\author{
Youngshin Lee1, Sanghee Shin ${ }^{*}$ \\ ${ }^{1}$ Department of Environmental Engineering, Hanseo University, Seosan-Si, Republic of Korea \\ ${ }^{2}$ Geotechnical Engineering Research Division, Korea Institute of Construction Technology, Goyang-Si, Republic \\ of Korea \\ Email: ${ }^{*}$ scott@kict.re.kr
}

Received 20 December 2013; revised 15 January 2014; accepted 12 February 2014

Copyright (C) 2014 by authors and Scientific Research Publishing Inc.

This work is licensed under the Creative Commons Attribution International License (CC BY). http://creativecommons.org/licenses/by/4.0/

(c) (†) Open Access

\section{Abstract}

This study, with Hongdong Reservoir, is intended to evaluate the changes in water quality in the lake before and after rainfall in summer. Various non-point source pollutions are scattered around the reservoir, and to determine the pollution level by pollution source, samples were taken at the same point before rainfall (1st), during rainfall (2nd) and after rainfall (3rd) and concentration was measured. Pollutant concentration curve at the measuring points (HDS1, HDS2, HDS3) appeared to be similar with the hydrological curve. When comparing the concentration immediately before rainfall with event mean concentration (EMC), SS and COD were 4 - 59 times and 1 - 4 times, respectively. However, when it comes to total nitrogen (T-N), concentration arrived at the reservoir stayed the range of $1.3-12.0 \mathrm{mg} / \mathrm{L}$ in all 3 cases without significant variation, which indicated that total nitrogen load is critical when arriving at the reservoir, irrespective of rainfall, and thus it's necessary to consider non-point source pollution runoff also in addition to point source pollution when developing the water quality improvement measures in reservoir.

\section{Keywords}

Rainfall Event; Reservoir Control; Water Pollution; Nutrients; Non-Point Pollution Source

\section{Introduction}

Reservoirs have been expanded and refurbished as part of the project to improve the water quality and integrated watershed management plan for water quality control was established and introduced. Nutrient salts contained in domestic sewage and industrial wastewater promote the propagation of plankton which increases eutrophication

\footnotetext{
*Corresponding author.
} 
or eutrophication effect. Retention area formed in man-made reservoir in a bid to control the water supply and the flood is known as one of the main factors degrading the water quality [1] [2].

As most of rainfall $(60 \% \sim 70 \%)$ in Korea is concentrated on summer season, considerable amount of pollutants originated from non-point pollution source at farmland or mountainous area have been discharged during rainfall duration. Because it's difficult to track the path of such non-point source and efflux varies irregularly, it's also difficult to determine the quantitative solution [3]-[5]. Particularly, the reservoir at farmland or mountainous area is used to hold the water for extended time during rainfall duration for agricultural use. Thus pollutants carried to reservoir with runoff also stay at reservoir and excessive nutrients cause eutrophication, deteriorating the water quality in reservoir. Given the pollutants are mostly from the runoff after initial rain, management technique to effectively deal with the pollutants during rainfall needs to be further developed [2].

In previous studies, water improvement projects using natural purification function were conducted. Vegetation around reservoir has been used as part of natural purification function [6] which also required integrated pollution source management and purification measures and consequently. Domestic study on runoff characteristics of non-point pollution source has made a considerable progress in a way of applying previously-developed technologies and verification, but the data on pollution contribution and loading in small farm reservoirs throughout the nation by non-point pollution source before and after rainfall. Therefore, it's necessary to investigate the pollutant concentration before/after rainfall in a bid to introduce effective reservoir water quality management through the disposal or isolate the runoff after initial rainfall.

This study, for reservoir water quality management, is aimed at identifying the characteristic of reservoir water pollution concentration before/after rainfall and estimating the nutrient salts so as to provide the base to use reservoir water quality management data.

\section{Territory and Methodology}

The points near the bridges which were easily accessible at three tributaries were designated for investigating water quality during rainfall at the basin around Hongdong Reservoir and the designated points for investigation are indicated in Figure 1 and the coordinates are in Table 1. The points for measuring water level and velocity for flow measurement were designated at the location where the flow was not interrupted from the reservoir as well as is accessible and easy to measure the water level and flow velocity. Three tributaries to Hongdong reservoir were designated to monitor the inflow rate and water quality. For estimating the flow arriving at the reservoir over extended time, water level-rating curve was developed so as to convert to the flow rate from water level. As there's a pier at the level monitoring point in Sangsongcheon, an inflow river to Hongdong Reservoir, water flows on right side of the pier but when depth reaches $20 \mathrm{~cm}$ or more, water also runs on the left side of the pier too. The stream is $7.5 \mathrm{~m}$ wide and the height from the bottom to the bridge deck is about $4.2 \mathrm{~m}$. Flow rate was measured when rain starts till the water level drops considerably after rain stopped ay hourly interval.

Water level was measured before/after monitoring flow rate and flow velocity was checked at the point with $60 \%$ of main stream in depth. Flow rate was estimated in a way of multiplying the measured level by flow velocity after calculating the sectional area using a cross sectional view. Figure 2 shows the distribution of daily rainfall at Hongdong Reservoir from June through Oct 2005. Table 2 outlines the dates and rainfall characteristics during rainfall events at Hongdong Reservoir. Figures 3-5 shows hourly rainfall during monitoring.

\section{Sampling the Runoff during Rainfall \& Quality Analysis}

Samples of runoff were taken at hourly interval along with measuring water level and flow velocity when rain started. As rain lasted for extended time, samples were taken and replaced at regular interval till the water level at the river dropped considerably and measuring water level and velocity and sampling were carried out at three

Table 1. Location of sampling near Hongdong reservoir.

\begin{tabular}{cc}
\hline \multicolumn{1}{c}{ Location } \\
\hline HDS 1 & N $36^{\circ} 30^{\prime} 34.28^{\prime \prime}$ E $126^{\circ} 42^{\prime} 13.93^{\prime \prime}$ \\
HDS 2 & N $36^{\circ} 30^{\prime} 27.32^{\prime \prime}$ E $126^{\circ} 42^{\prime} 07.16^{\prime \prime}$ \\
HDS 3 & N $36^{\circ} 30^{\prime} 24.77^{\prime \prime}$ E $126^{\circ} 41^{\prime} 47.80^{\prime \prime}$ \\
\hline
\end{tabular}




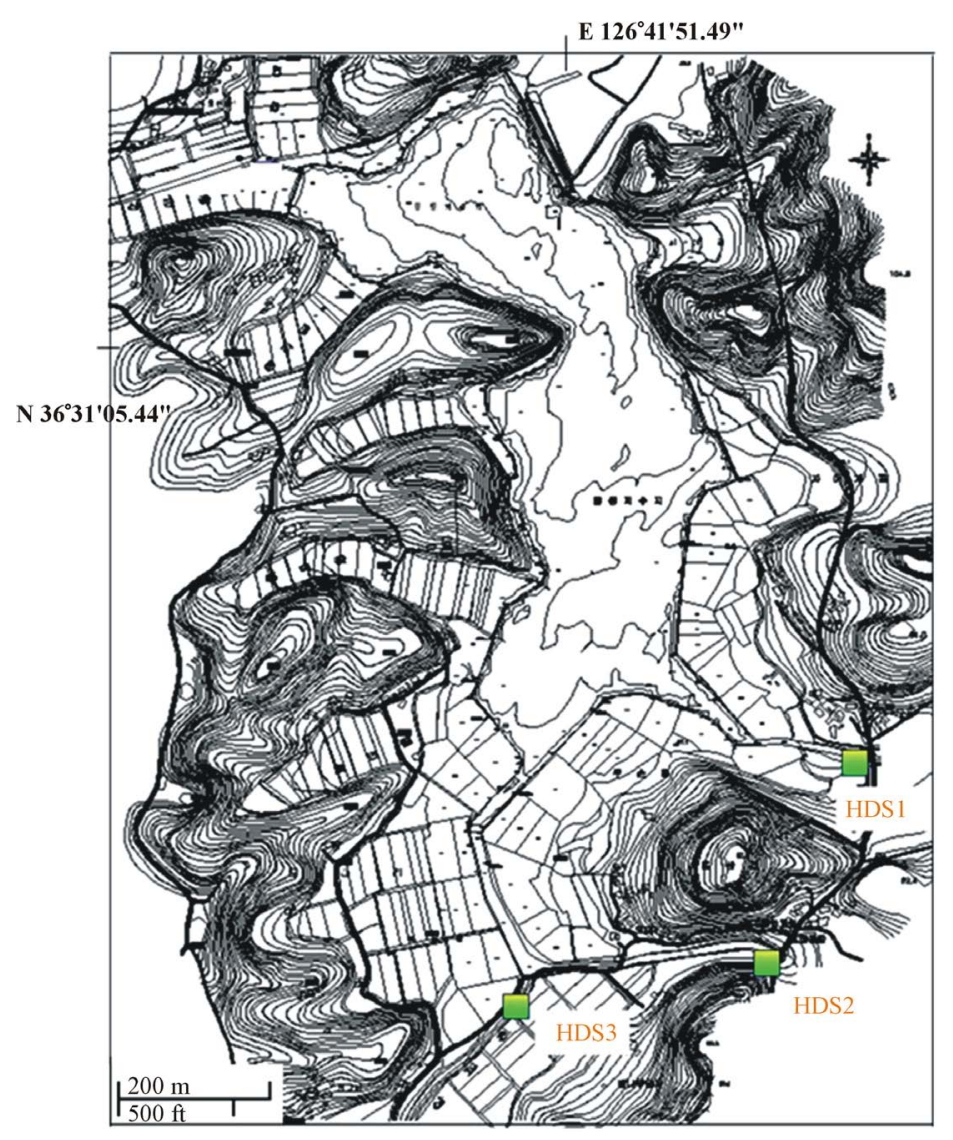

Figure 1. Sampling location at Hongdong reservoir (square: location of the investigation).

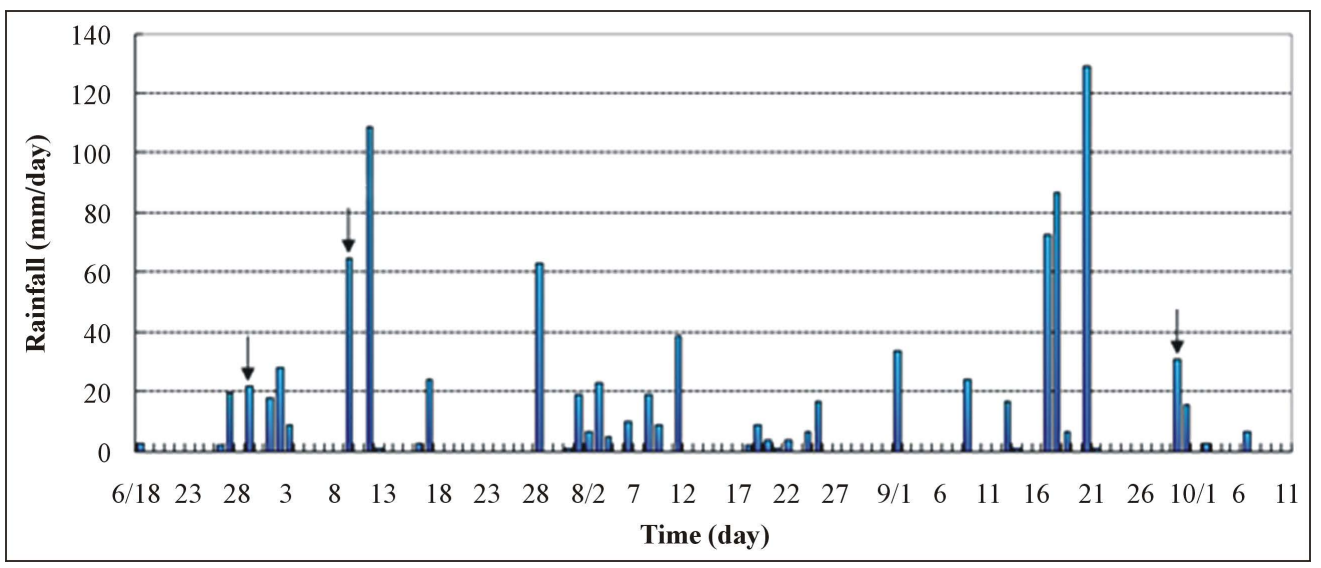

Figure 2. The amount of rainfall measured from June to October at Hongdong reservoir.

Table 2. Rainfall characteristics during the investigation period.

\begin{tabular}{ccccccc}
\hline Runoff & Event & $\begin{array}{c}\text { Rainfall } \\
(\mathrm{mm})\end{array}$ & $\begin{array}{c}\text { Duration } \\
(\mathrm{hr})\end{array}$ & $\begin{array}{c}\text { Mean rainfall } \\
\text { intensity }(\mathrm{mm} / \mathrm{hr})\end{array}$ & $\begin{array}{c}\text { Anterior rainfall } \\
\text { volume }(\mathrm{mm})\end{array}$ & $\begin{array}{c}\text { Continuous rainfall } \\
\text { characteristics like dry days (day) }\end{array}$ \\
\hline $1^{\text {st }}$ & ${\text { June } 29^{\text {th }}}$ & 22 & 3 & 7.33 & $2(20)$ & 2 \\
$2^{\text {nd }}$ & July $9^{\text {th }}$ & 65 & 13 & 5.00 & 9 & 6 \\
$3^{\text {rd }}$ & ${\text { September } 30^{\text {th }}}$ & 47 & 19 & 2.47 & 1 & 7 \\
\hline
\end{tabular}




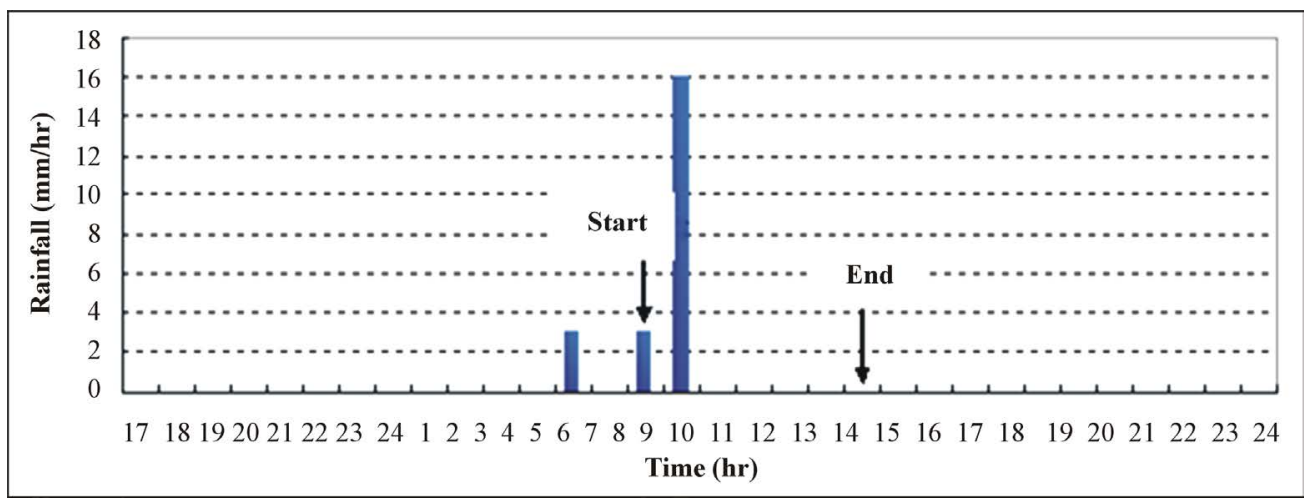

Figure 3. Rainfall measured in the 1st at Hongdong reservoir.

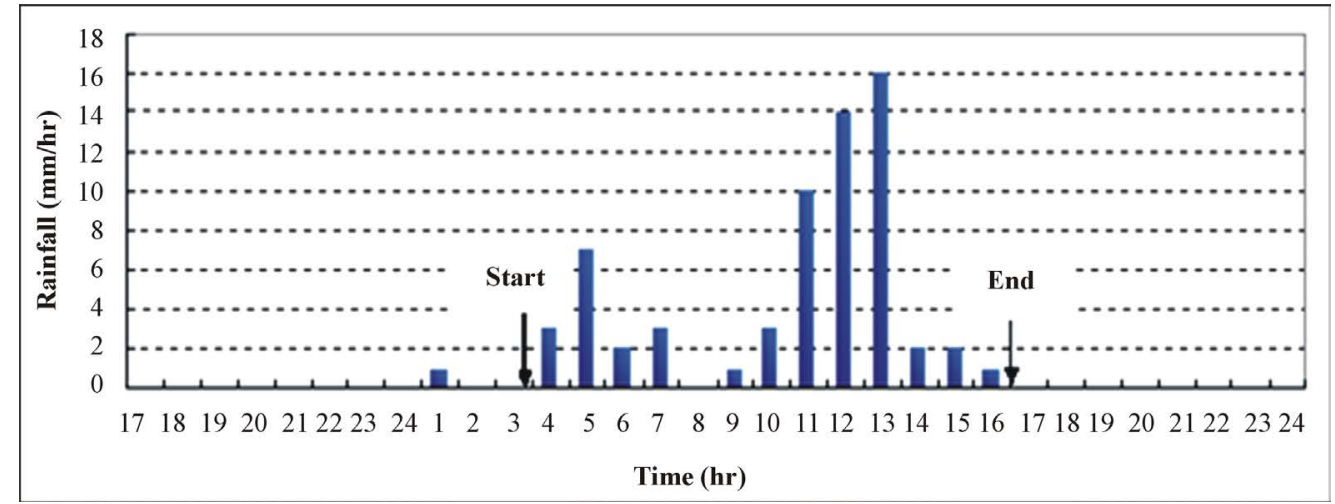

Figure 4. Rainfall measured in the 2nd at Hongdong reservoir.

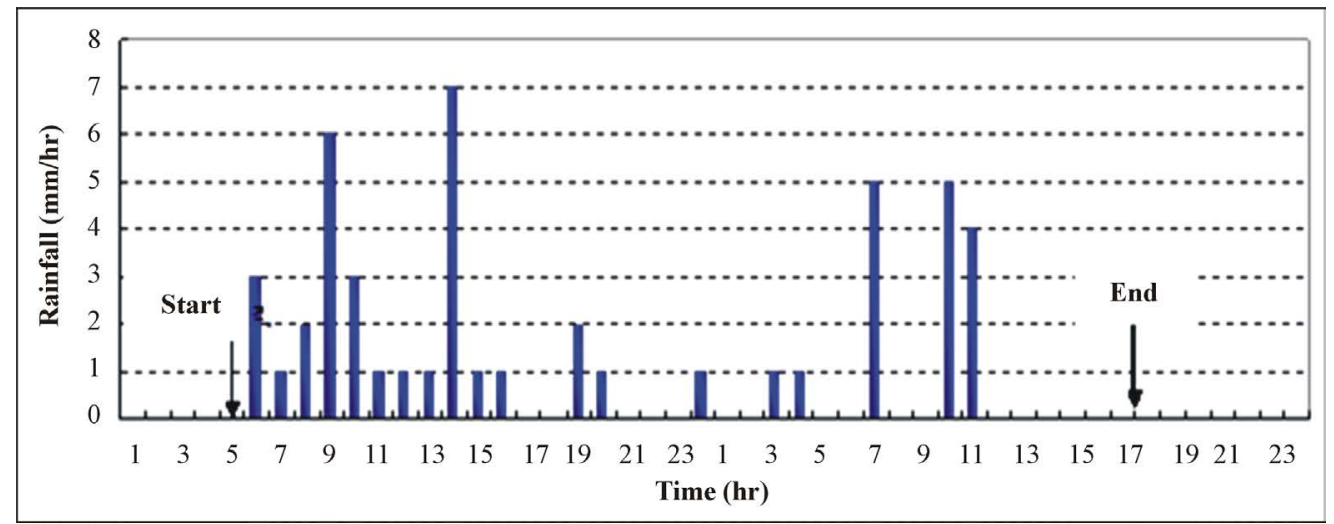

Figure 5. Rainfall measured in the 3rd at Hongdong reservoir.

tributaries flowing into Hongdong Reservoir.

Water quality analysis of runoff during rainfall was conducted using Official Analysis Method for Water Pollutants COD indicating the content of organic materials in sample was measured using manganate method [7]. Total nitrogen (T-N) was analyzed in a way of decomposing in high pressure sterilizer after putting the sample in bottle and adding alkali potassium persulfate and ultraviolet absorption (general spectronic 123) was measured and analyzed, and ammonia nitrogen was analyzed using indophenol test. Nitriteand nitrate were also analyzed using diazoa method and brucine method. For analysis of total phosphorus (T-P), ascorbic acid reduction method was used after decomposing according to Official Analysis Method for Water Pollutants. Concentration of phosphorate-phosphrous was calculated after filtering and coloring using ascorbic acid reduction method and measuring the optical density. TDS and $\mathrm{pH}$ were measured using HACH TDS meter and Orion $301 \mathrm{pH}$ meter, 
respectively and alkalinity in water was analyzed using $0.025 \mathrm{~N}$ sulfuric acid solution.

\section{Characteristics of Non-Point Source Pollutants from Rainfall Event}

Characteristics of pollutants at certain basin area for certain rainfall event are represented by peak concentration, mean concentration, peak load, mean load or sum of load, which are indicated in graph showing hydrograph, pollutograph and loadgraph in Figure 6. Then in most of cases, total load from rainfall event is more important than concentration or peak load because given the mixing to some extent in water body, particularly in reservoir or lake where runoff event is relatively short and rainfall runoff joins, pollutant concentration is rather the response to the total load than influence by changes in concentration in runoff (into the reservoir) by rainfall. For nutrients such as nitrogen or phosphoric in reservoir or lake, total load is the most influential variable to water quality and thus total load is considered the most appropriate factor in evaluating the non-point source pollutants with event mean concentration (EMC) and has been widely used. EMC of pollutants is calculated as follows [8].

$$
\mathrm{EMC}=(\text { Total load of pollutants in total runoff }) /(\text { total runoff })=\sum \mathrm{Q}_{\mathrm{i}} \mathrm{C}_{\mathrm{i}} / \sum \mathrm{Q}_{\mathrm{i}}
$$

Where, $\mathrm{Q}_{\mathrm{i}}=$ runoff during micro time on hydrological curve $\left(\mathrm{m}^{3} / \mathrm{hr}\right)$

$\mathrm{C}_{\mathrm{i}}=$ Pollutant concentration on runoff curve in response to $\mathrm{Q}_{\mathrm{i}}(\mathrm{mg} / \mathrm{L})$

$\mathrm{EMC}=$ Mean concentration for rainfall event $(\mathrm{mg} / \mathrm{L})$

Table 3 suggests characteristic of runoff, EMC and load analyzed at each point during rainfall. Viewing EMC on Table 3, peak flow and total runoff volume appeared to be influenced.

\section{Investigation and Analysis of Runoff Effect}

In urban area where the area is mostly impervious and rainwater and sewage are drained using separate or combined system, the capacity of detention system using the runoff during initial rainfall (or first flush flow) is determined by the amount of suspended solid pollutant during initial rainfall. When pollutants which are easily

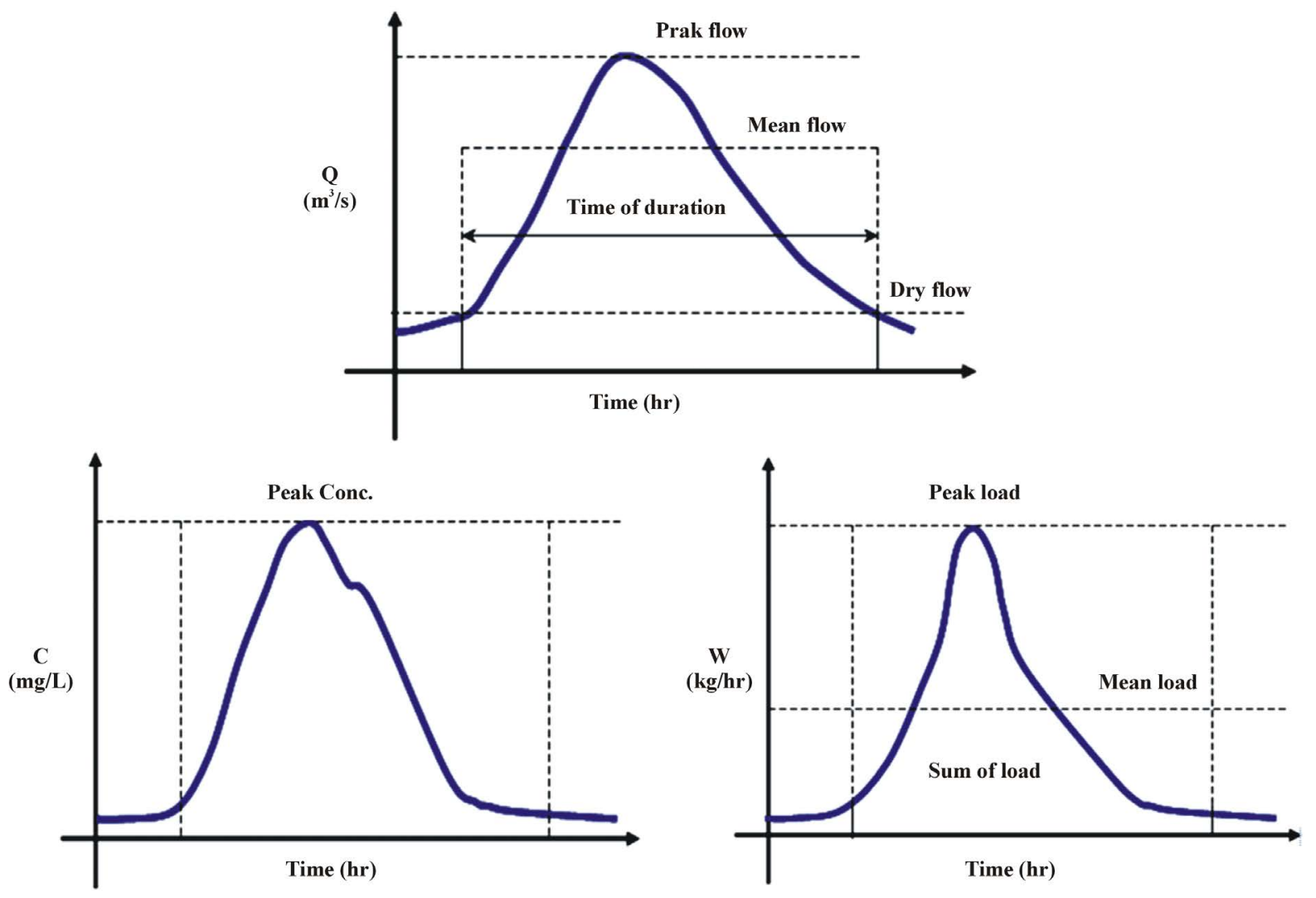

Figure 6. Comparison volume, concentration and weight (loading) at rainfall event. 
Table 3. Runoff characteristics of pollutants at HDS1.

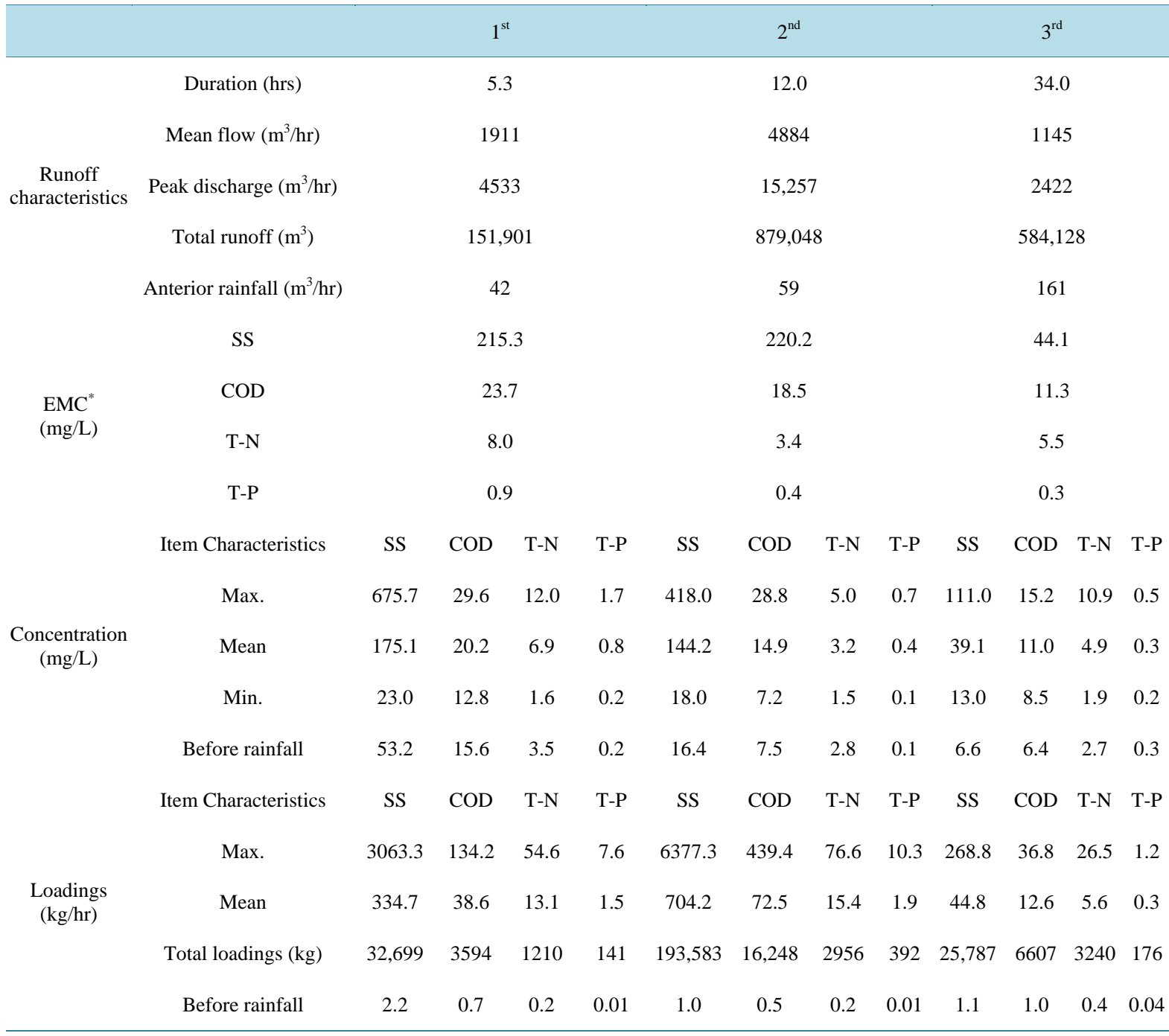

washed away by runoff exist at drainage region, peak concentration and load appear prior to reaching to peak flow and thus if designed with tolerable critical concentration or load capacity (for instance, $90 \%$ capacity in Germany), it would be very efficient in determining the capacity $\left(\mathrm{m}^{3}\right)$ to deal with non-point source pollutants.

To identify the existence of initial rainfall runoff effect, investigation of time difference between peak flow rate and peak load after overlapping SS, COD, T-N and T-P load curve on hydrological curve. Figures 7-9 show is the result after overlapping pollutant load curve on hydrological curve using the data analyzed during the $1^{\text {st }}$ rainfall at Hongdong Reservoir.

According to Figures 7-9, no time difference between peak flow and peak load which could prove the effect of initial rainfall runoff at farm reservoir area appeared to all rainfall events. And no cleaning effect between rainfall events at same basin area appeared, but reduction in load was much larger when flow was reduced than the case of flow rising.

\section{Conclusion and Consideration}

In this study, investigation was conducted at Hongdong Reservoir to identify the pollutant discharge and distribution of the volume over time and the effect of initial rainfall runoff sampling of runoff during rainfall was arranged at regular interval when monitoring water level and flow velocity during rainfall and the sample representing peak flow was included. As rainfall duration is extended, the samples were selected at equal time inter- 

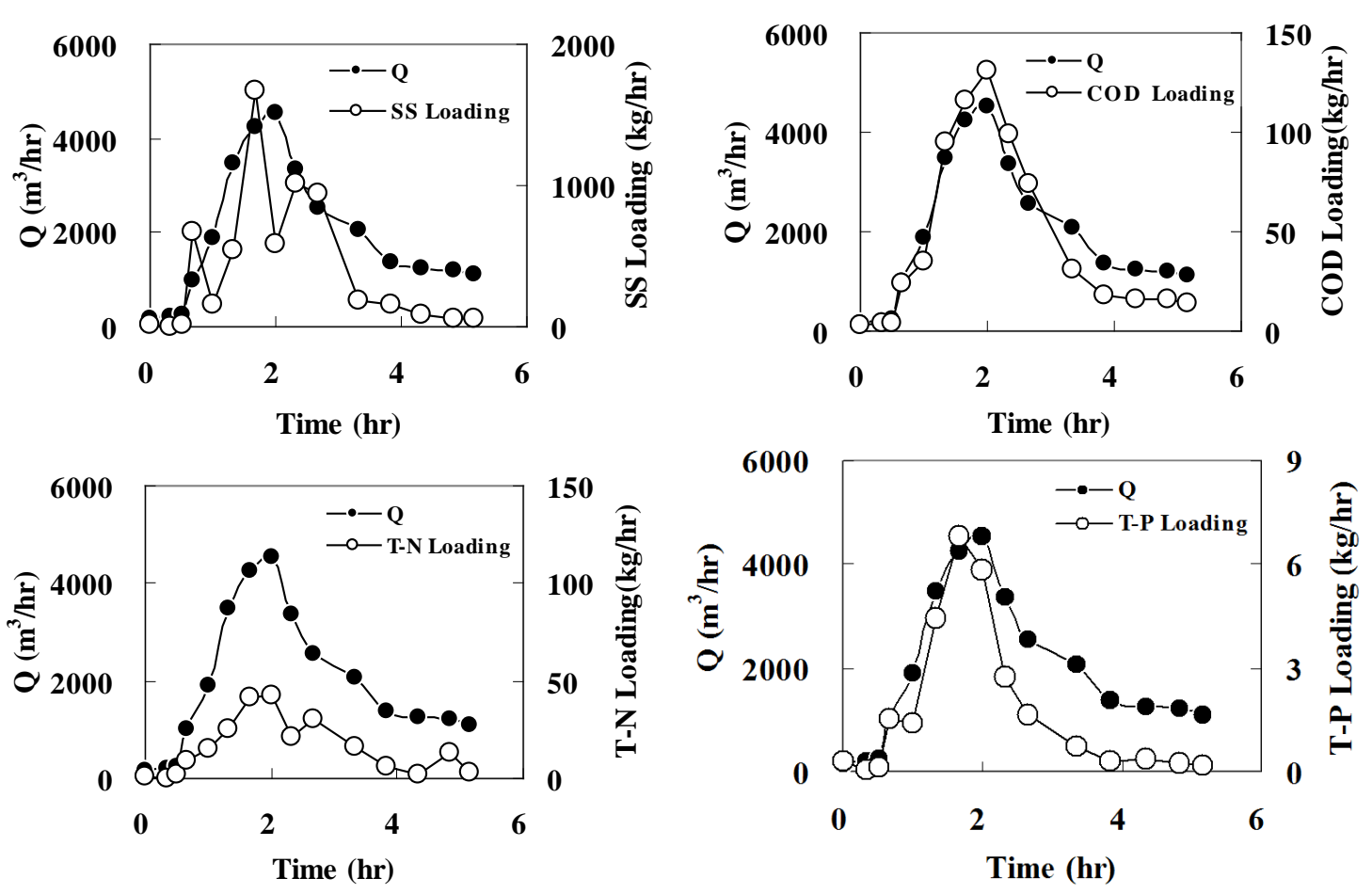

Figure 7. Distribution of time vs. flow and loadings at HDS1 ( $1^{\text {st }}$ investigation).
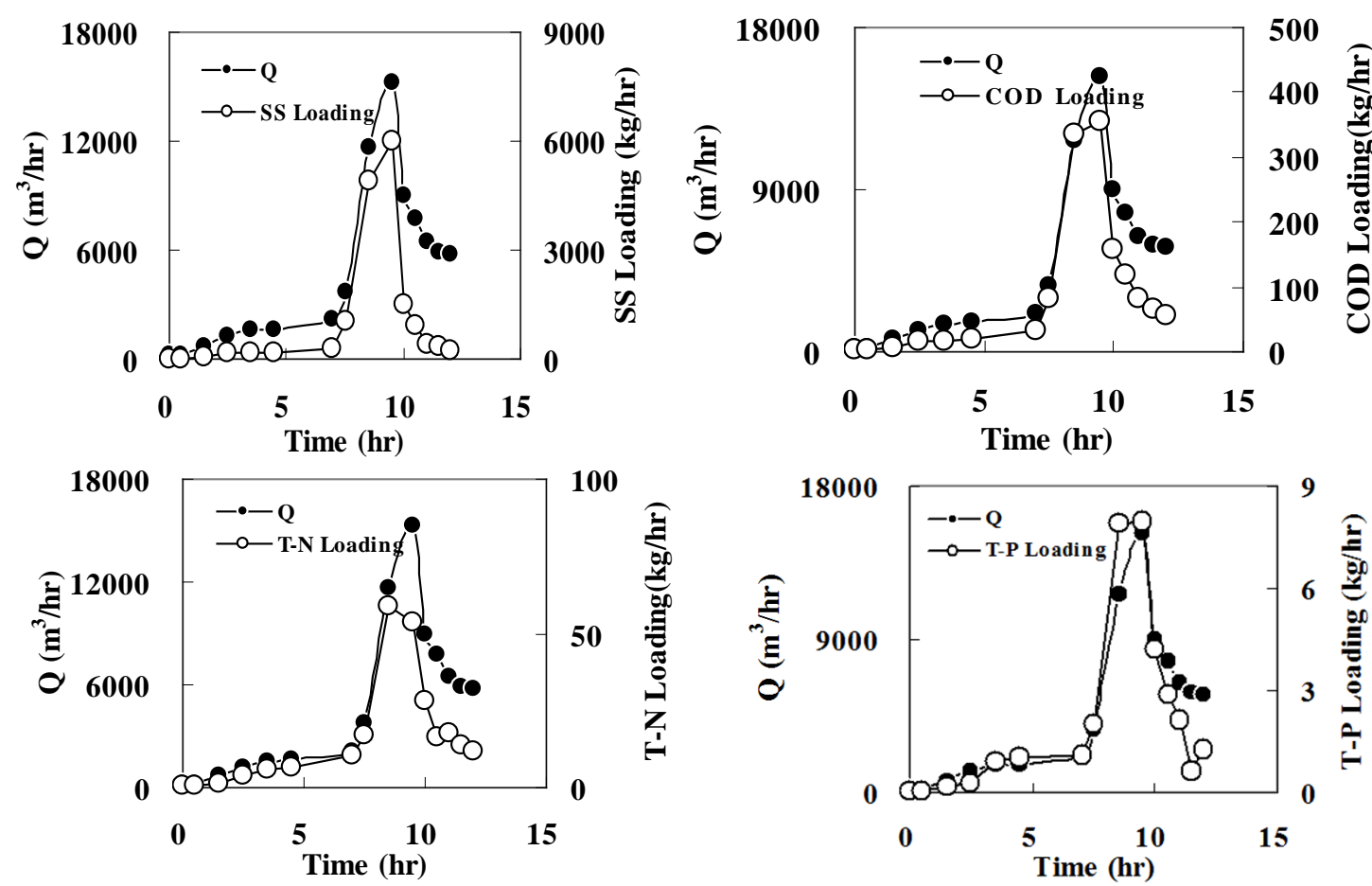

Figure 8. Distribution of time vs. flow and loadings at HDS1 ( $2^{\text {nd }}$ investigation).

val for replacement till the water level dropped sufficiently after rain stopped. Included in the items for analysis were SS, COD, SCOD, nitrogen, total phosphorous and phosphorate phosphorous. Samples were taken three times at each basin area on June 28, July 9 and September 30, 2005. During rainfall at investigation sites, hydrological curve and SS, COD, T-P concentration curve pattern (rise-fall) appeared the same. But with regard to ni- 

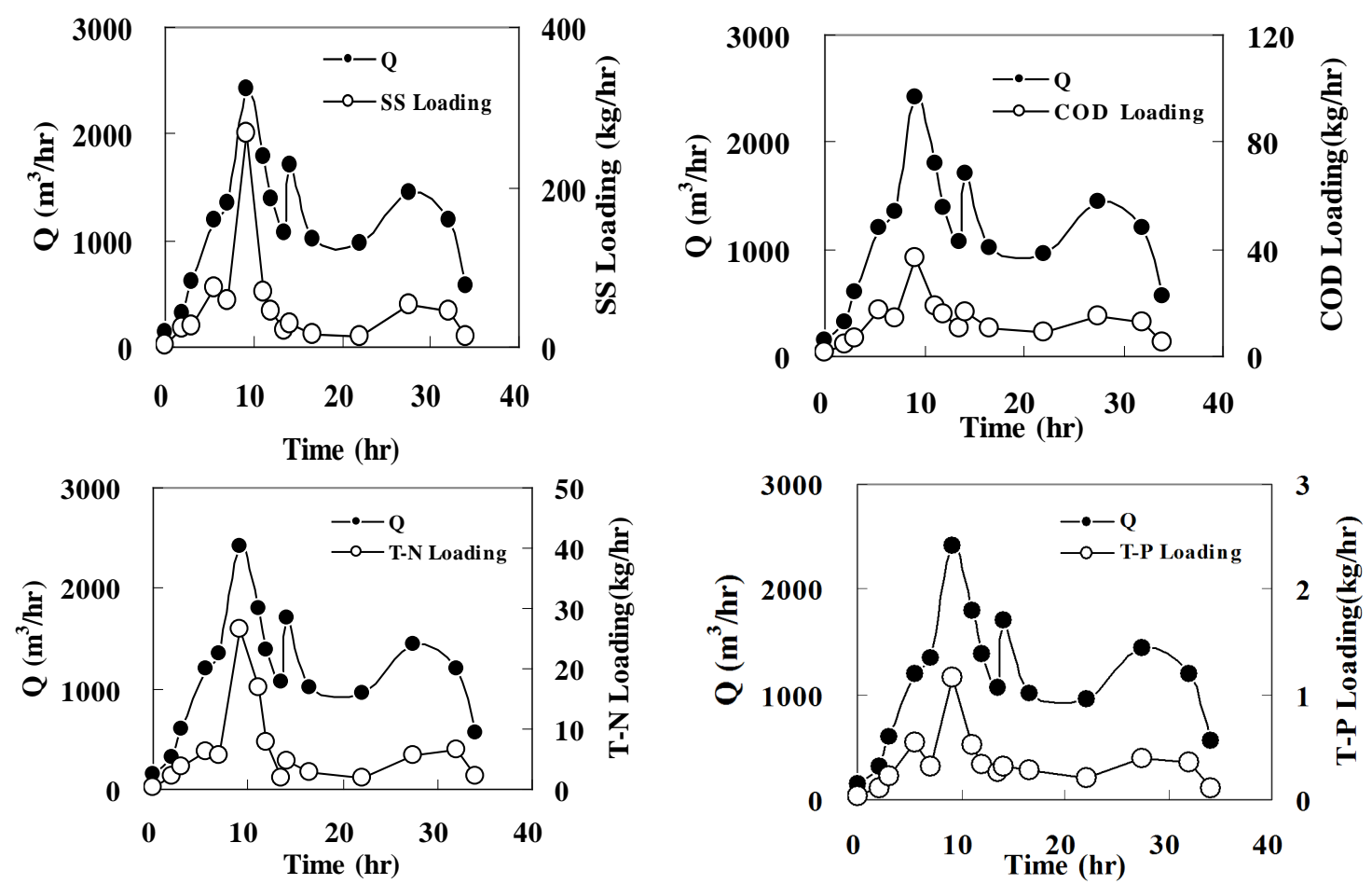

Figure 9. Distribution of time vs. flow and loadings at HDS1 ( $3^{\text {rd }}$ investigation).

trogen concentration, inflow rate during non-rainfall was also an important factor, besides runoff during rainfall, irrespective of runoff volume during rainfall and non-rainfall, which shall be considered in establishing the measure to deal with the non-point source pollutants. Moreover, identifying the characteristics of pollutants flowing into the reservoir is very important in establishing the disposal plan.

According to the analysis of correlation between data on SS and COD \& T-P collected during rainfall, pollutants were mostly carried by granular materials, which was attributable to suspended material and soil transported by rainfall energy or kinetic energy of runoff and thus retarding basin at upper stream of the reservoir, if installed, would possibly reduce the organic material and total phosphorous load arrived at the reservoir. But for management of reservoir in steady manner, the facilities to deal with domestic sewage, livestock manure and non-point source pollutants to dispose of illegal discharge or on road are more than important.

The data on characteristics of runoff during rainfall and pollutants including contamination load presented in this study would help establish the reservoir management plan and the data on characteristics \& concentration of pollutants and total sediment deposit from the investigation of sediment deposit would provide the basic data in determining the dredging in reservoir or reuse. However, given that this study includes the data obtained from rainfall during short time and the measurements were limited, it may be partially difficult to analyze the findings and thus more in-depth and long-term studies are required to supplement such challenges.

\section{Acknowledgements}

This study was conducted as part of the project supported by the Korea Rural Community Corporation for which we extend the deepest gratitude.

\section{References}

[1] Kwon, S.K. (1998) Management Improvement and Perspective on Nonpoint Sources of Water Pollution. Korean Society of Environmental Engineers, 20, 1497-1510.

[2] Lee, Y.S. and Shin, S.H. (2013) Effective Reservoir Management Methods Using Nutrients Leaching Characteristic Analysis: Case Study of the Hongdong Reservoir. The Journal of Engineering Geology, 23, 95-104. http://dx.doi.org/10.9720/kseg.2013.2.95 
[3] Fulcher, G.A. (1994) Urban Storm Water Quality from a Residential Catchment. The Science of the Total Environment, 146-147, 535-542. http://dx.doi.org/10.1016/0048-9697(94)90279-8

[4] Pegram, G.C., Quibell, G. and Hinsch, M. (1999) The Nonpoint Source Impacts of Peri-Urban Settlements in South Africa: Implications for Their Management. Water Science Technology, 39, 283-290. http://dx.doi.org/10.1016/S0273-1223(99)00345-5

[5] Qin, H.P., Khu, S.T. and Yu, X.Y. (2010) Spatial Variations of Storm Runoff Pollution and Their Correlation with Land-Use in a Rapidly Urbanizing Catchment in China. Science of the Total Environment, 408, 4613-4623. http://dx.doi.org/10.1016/j.scitotenv.2010.07.021

[6] Park, B.H. (2000) Analyse of Water Purification Techniques and Their Applicability in Lakes and Reservoirs Using a Water Quality Model. Seoul National University, Seoul, 152.

[7] Ministry of Environment (2004) Standard Methods. No. 2004-188 of the Ministry of Environment, 1205.

[8] National Institute of Environmental Research (2006) Evaluation of Non-Point Sources Loadings (1)-Impervious Land No. 2006-34-816 of National Institute of Environmental Research, 103. 